\title{
Effect of seasonal radiation and daylenght shifts on growth and development of spray carnation. 1. Vegetative growth
}

\author{
D. Klapwijk
}

Glasshouse Crops Research Station P.O. Box 8, 2670 AA Naaldwijk, Netherlands

Received 20 January 1986; accepted 12 December 1986

Key-words: spray carnation, season, growth, leaf initiation, stem length, flower growth

\begin{abstract}
Growth and development of 32 year-round plantings of spray carnation (Dianthus caryophyllus L. cv. West Pink) were determined. Relative growth rate of carnation shoots was strongly affected by the season. The minimum rate was approximately $2 \%$ per day in December and increased linearly to almost $9 \%$ in mid-summer. After the summer maximum, it decreased linearly again to $2 \%$ in December. Leaf initiation rates showed the same pattern with a minimum of 0.09 and a maximum of 0.24 leaf pairs per day. Stem elongation also fitted in two linear functions with a minimum of about $0.1 \mathrm{~cm} \mathrm{day}^{-1}$ in winter and a maximum of slightly less than $0.5 \mathrm{~cm}$ $\mathrm{day}^{-1}$ in summer. The growth period between microscopically visible initiation of the flower bud and full bloom is also included in this paper because flower growth reacts in a vegetative manner like shoot growth, leaf initiation and extension of the vegetative shoot.
\end{abstract}

\section{Introduction}

Much work has been done on the effect of artificial variation in day length on flower initiation of carnation since Blake published her results in 1955. She proved that there is a definite daylength effect on the number of leaf pairs before the flower is initiated. No data, however, were available on the influence of the seasonal shift in daylength on flower initiation. With improved knowledge about the effect of natural daylength on flower initiation it may be possible to make better use of artificial daylength extension. This may allow flower production peaks to be spread over periods of lower production and higher prices.

When collecting year-round data concerning flower initiation it would have been a wasted oppertunity not to determine vegetative growth rates of this slow-growing species at the same time. These data can then be compared with already available year-round series on vegetative growth of different vegetable crop plants with high- 
er growth rates.

In the present paper results concerning vegetative growth of spray carnation are presented and evaluated. A descripton of the seasonal effects on flower initiation will be presented in a subsequent contribution (Klapwijk, 1987b).

\section{Materials and methods}

In order to collect year-around data on flower initiation, young rooted cuttings of spray carnation (Dianthus caryophyllus L. cv. West Pink) were planted in containers with a fertilized peat substrate, successively between September 1982 and July 1984. Pinching occurred as soon as the cuttings were established. The date of pinching was considered as day 1 of the experiments. Only one shoot per plant was maintained, of which data were collected on fresh weight, length, number of leaf pairs (microscopically, $\times 20$ ), flower initiation and time of flowering. Between pinching and flowering, depending on growth rates, 10-18 samples of 10-12 plants each, were taken at regular intervals. The regular sampling kept plant density so low that no or only very little light competition beteen plants in the stand occurred. Growing conditions were similar to those of commercial carnation nurseries in the Netherlands. The glasshouse light transmission was approximately $65 \%$ of the natural radiation under diffuse light conditions.

\section{Results and discussion}

\section{Growth rates of whole plants}

In Fig. 1 the data on the relative growth rate (RGR) are presented. The RGR is determined for the period during which fresh weight increased from 1 to $10 \mathrm{~g}$ fresh weight per plant because higher weights interfered with flower initiation. The RGR is plotted against the day number in the middle of the growth period during which fresh weight increased from 1 to $10 \mathrm{~g}$ per plant (mid-date; Klapwijk, 1979, 1981). Growth rates ranged from about $2 \%$ over a 120 -day period in the middle of the winter to almost $9 \%$ around the longest day in summer. Growth rate and time of the season were closely related. Solar radiation is obviously the most important seasonal factor affecting growth. The effect of the season on growth rate is presented as a two-sided linear curve, altough a curvilinear presentation would also have been possible. The first presentation, however, is much easier in crop planning whilst the accuracy of data-fitting is approximately the same in these two presentations.

The growth rate of carnation is much lower than that of rapidly-growing species such as tomatoes, and the seasonal growth pattern also is different (Klapwijk, 1981). This difference is most pronounced in summer when carnations respond to the increasing solar radiation and young tomato plants do not. This is most likely due to the fact that tomato responds to increasing solar radiation by increases in leaf thickness while carnation does not. (Bruggink, personal communication). Radish under glass is also sensitive to radiation differences in summer (Klapwijk, unpublished). The two-sided linear relationship in winter was found for several 


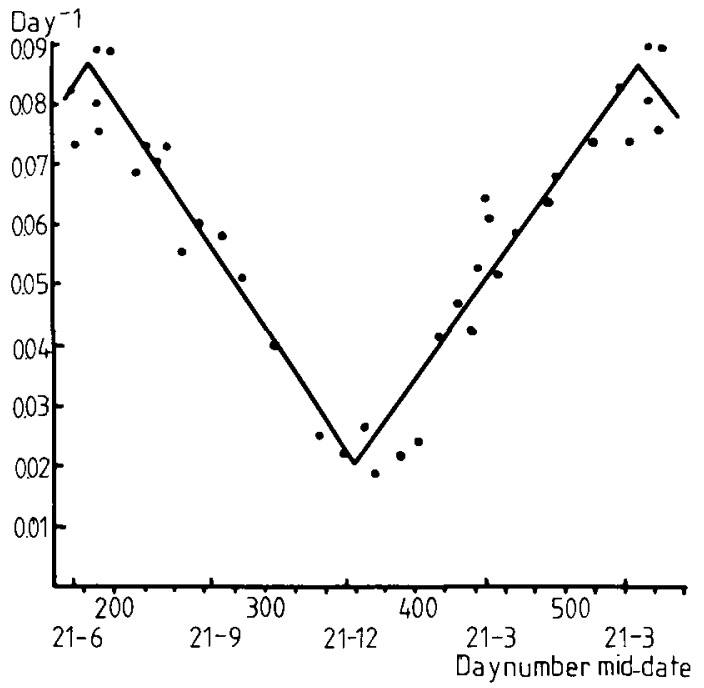

Fig. 1. Relative growth rate $\left(\right.$ day $\left.^{-1}\right)$ of carnation shoots, between 1 and $10 \mathrm{~g}$ fresh weight. Regression equations:

$190 \leqslant x \leqslant 352 ; y=-0.0380 x+15.6 \quad r=0.960$

$372 \leqslant x \leqslant 538 ; y=0.0346 x-12.1 \quad r=0.941$

other crops such as cucumber (Klapwijk \& van Berkel, 1983), lettuce (Klapwijk, 1979), chrysanthemum (Klapwijk, 1987a), and roses (van den Berg \& Valentin, personal communication).

Bunt (1972) also determined year-round growth rates of carnation. Those data, when plotted against the mid-date, do not fit in our Fig. 1. This discrepancy is pro-

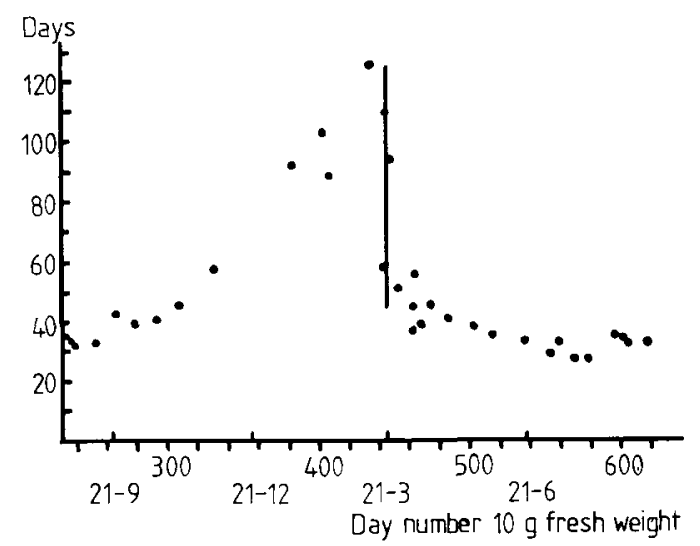

Fig. 2. Growth period (days) of carnation shoots, between 1 and $10 \mathrm{~g}$ fresh weight, in relation to the $10 \mathrm{~g}$ fresh weight date. 


\section{KLAPWIJK}

bably due to the fact that Bunt's calculation of the RGR is based on only two weight determinations 27 days apart, the first one being too early after planting when plants do not grow at a normal rate. Plants require at least a week after planting to resume growth; the RGR will therefore not have been constant over the 27 days.

The very low growth rates of carnation in winter can be demonstrated with a presentation of data as in Fig. 2. In this figure the duration of the period during which fresh weight of a carnation shoot increased from 1 to $10 \mathrm{~g}$ is plotted against the date at the end of the growth period when the shoot reached $10 \mathrm{~g}$ fresh weight. For plants reaching $10 \mathrm{~g}$ later than September the duration of the growth period increased for later plantings from approximately 40 to more than 120 days. For plants reaching $10 \mathrm{~g}$ on 21 March there were differences in age from 120 to 50 days. On 21 March no reliable difference could be observed between plants pinched between 21 November and 1 February. The very low growth rate during winter implies that there are no practical possibilities for a substantial increase in flower production in winter by means of artificial daylength extension. Genetic improvement of the light use efficiency in carnation may offer a solution to this problem.

\section{Leaf pair initiation rate}

Fig. 3. shows the leaf pair initiation rate plotted against the mid-date for the range between 10 and 20 leaf pairs counted from the shoot base. This period was chosen because it corresponded with the growth period from 1 to $10 \mathrm{~g}$ fresh weight (Fig.

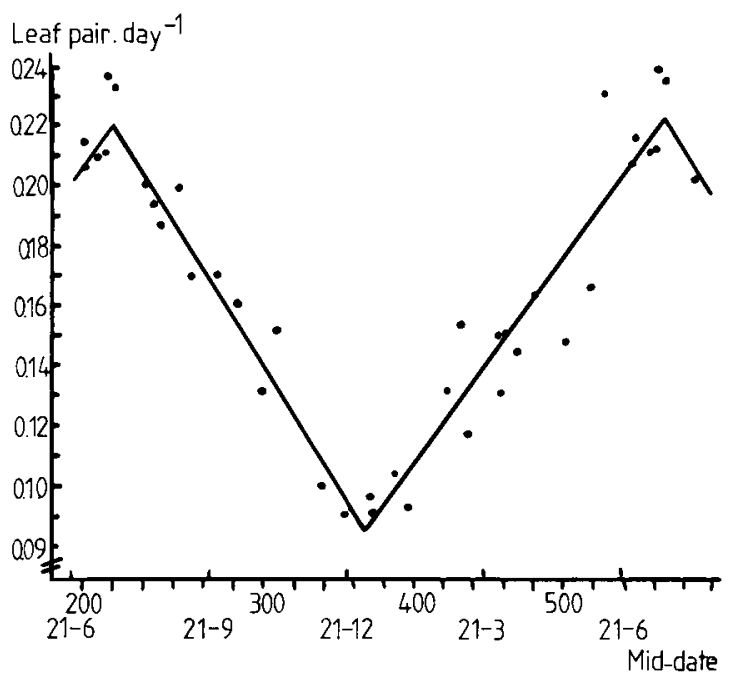

Fig. 3. Leaf initiation rate (leaf pairs per day) of carnation shoots, between leaf number 10 and 20 . Regression equations:

$\begin{array}{lrl}204 \leqslant x \leqslant 356 ; y= & -0.000853 x+0.397 & r=0.970 \\ 374 \leqslant x \leqslant 565 ; y= & 0.000677 x-0.164 & r=0.943\end{array}$ 


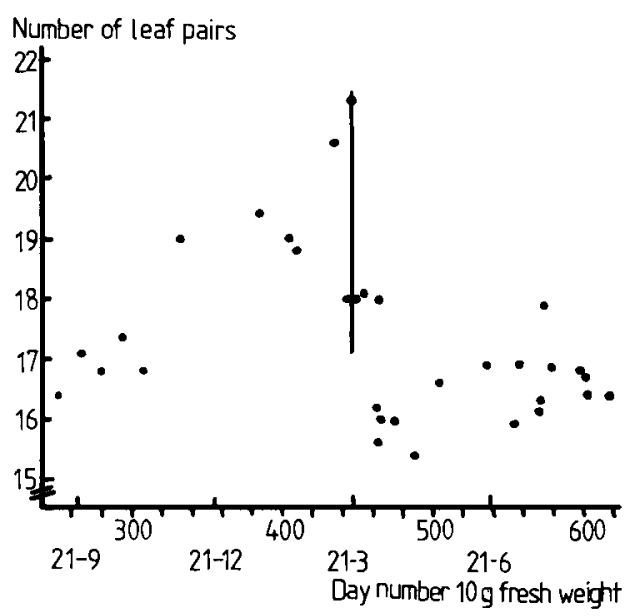

Fig. 4. Number of leaf pairs in vegetative carnation shoots, in relation to the $10 \mathrm{~g}$ fresh weight date.

1.). Flower initiation sometimes took place a little earlier than the appearance of the 20th leaf. Leaf initiation rate was then taken until flower initiation. The relation is described by two linear functions comparable to Fig. 1. Analogous to the RGR, the rates of leaf pair initiation were strongly dependent on solar radiation. The difference is that the ratio between winter and summer growth rates is $1: 5$ for fresh weight (Fig. 1) and $1: 2.5$ for leaf growth rates (Fig. 3). This implies a change in leaf size as the leaf area per gram plant does not change with different light levels (Bruggink, personal communication). This is demonstrated in Fig. 4, where the number of leaf pairs per plant at $10 \mathrm{~g}$ fresh weight is plotted against the date on which $10 \mathrm{~g}$ fresh weight was reached. As in Fig. 2, an abrupt decrease is shown on $21 \mathrm{March}$. As soon as the growth rates increased, leaf size also increased. Research concerning genetic adaptation for better carnation production rates should therefore be pointed at improving the light use efficiency with respect to both fresh weight growth rate and leaf initiation rate.

In two plantings of spray carnation $\mathrm{cv}$. West Pink, one under good and one under poor sunlight conditions, a comparison has been made with the standard carnation cv. White Sim. The leaf initiation rates for West Pink and White Sim were 0.206 and 0.206 leaf pairs per day in summer and 0.0946 and 0.0922 leaf pairs per day in winter respectively. It may thus be concluded that there are no substantial differences in leaf initiation rates between the two cultivars.

\section{Stem extension rate}

The stem extension rate was calculated for the vegetative shoot. The year-round data are presented in Fig. 5, plotted against the mid-date of the growth period between the moment the shoot reached $15 \mathrm{~cm}$ and the moment of flower initiation (Klapwijk, 1987b). The relationship with the season is again characterized by two linear functions, and a strong effect of seasonal radiation on extension growth rate 


\section{KLAPWIJK}

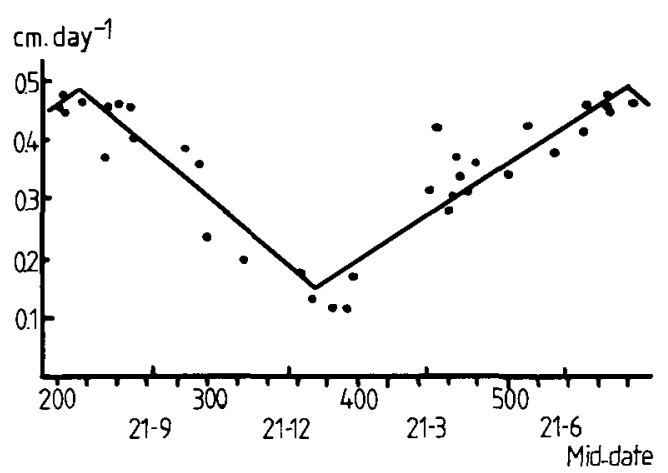

Fig. 5. Extension growth rate $\left(\mathrm{cm} \mathrm{day}^{-1}\right)$ of vegetative carnation shoots, between $15 \mathrm{~cm}$ and the moment of flower initiation. Regression equations:

$216 \leqslant x \leqslant 392 ; y=-0.00214 x+0.941 \quad r=0.958$

$370 \leqslant x \leqslant 566 ; y=0.00168 x-0.472 \quad r=0.917$

of the stem is demonstrated. The number of leaves initiated increased from winter to summer by a factor of about 2.5 , but elongation rates by a factor of 4 . Probably internode length of the vegetative shoot is smaller in winter than in summer. Bunt (1972) also measured year-round lengths of carnation shoots, but only at the moment of flowering. Therefore no reliable extension growth rate of the vegetative shoot could be calcultated. In Bunt's experiment with cv. White Sim, the total length increased from 70 to $94 \mathrm{~cm}$ between flowering in early August and June next year. In our work these lengths were 72 and $88 \mathrm{~cm}$, respectively.

\section{Period between flower initiation and flowering}

The growth period between flower initiation and full bloom depends on the season in a similar way as described above for other growth characteristics. Therefore

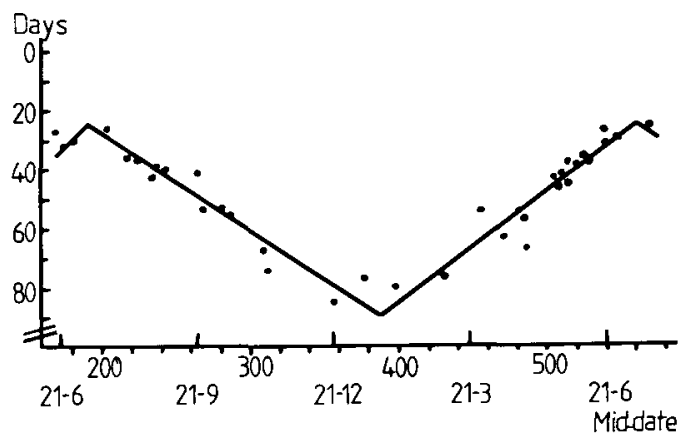

Fig. 6. Growth period (days) from flower initiation till full bloom of carnation. Regression equations: $203 \leqslant x \leqslant 377 ; y=0.327 x-37.2 \quad r=0.959$ $398 \leqslant x \leqslant 546 ; y=-0.374 x+23.4 \quad r=0.934$ 
these data are included in this paper. The data are shown in Fig. 6, again plotted against the mid-date. Growth periods from initiation to flowering are influenced by the seasonal radiation, analogous to fresh weight and leaf initiation. When the same presentation is made for the stage between pinching and flower initiation no such close correlation with seasonal radiation was found (Klapwijk, 1987b). Although flower growth may be considered as a generative process, these data warrant the conclusion that flower growth of carnation between initiation and full bloom reacts obviously in the same manner as the vegetative phenomena described above.

Deviaton from shortest and longest day

It should be noted in Fig. 1, 3, 5, and 6 that minimum and maximum rates do not exactly correspond with the occurrence of the winter and summer solstices. The average date of the minimum rates was 6 January, 16 days after the shortest day. In summer the average of the maximum rates fell on 17 July which is 26 days after the longest day. The exact explanation for this delayed plant reaction is not known. One possibility is that the use of the mid-date is not completely justified in this case because growth is not exactly linear. The small difference in solar radiation in autumn and spring may also be responsible for some deviation. It is also possible that the effects of radiation on carnation growth in autumn are different from those in spring, because in autumn the highest radiation coincides with the more efficient younger stage. In spring the reverse is true. Nevertheless, plotting against mid-date proved to be a convenient way of demonstrating the influence of the season on carnation growth.

\section{Conclusions}

The effect of season on the fresh weight growth rates and leaf initiation rates of spray carnation can be characterized by a two-sided linear relationship. The maximum and minimum growth rates occur in mid-summer and mid-winter, respectively.

The effect of season on flower growth between initiation and full bloom is similar to that of fresh weight and leaf initiation.

Fresh weight growth rates and leaf initiation rates of spray carnation are very low in comparison to other species.

It may be worthwhile to improve light use efficiency through breeding.

Standard carnations probably react similarly to the season as spray carnations.

\section{Acknowledgements}

The author wishes to thank Francisca Wubben for accurate assistance in the collection of the data, and Weststek BV for supplying the great number of rooted carnation cuttings required for this research. 


\section{KLAPWIJK}

\section{References}

Abou Dahab, A. M., 1967. Effects of light and temparature on growth and flowering of carnation (Dianthus caryophyllus L.). Communications Agricultural University, Wageningen 67-13, 68 pp.

Blake, J., 1955. Photoperiodism in perpetual-flowering carnation. Proceedings 14 th International Horticultural Congress (Netherlands): 331-336.

Bunt, A. C., 1972. Effect of season on the carnation (Dianthus caryophyllus L.). I. Growth rate. Journal of Horticultural Science 47: 467-477.

Klapwijk, D., 1979. Seasonal effects on the cropping-cycle of lettuce in glasshouses during the winter. Scientia Horticulturae 11: 371-377.

Klapwijk, D., 1981. Effect of season on early tomato growth and development rates. Netherlands Journal of Agricultural Science 29: 179-188.

Klapwijk, D., 1987a. Effect of season on growth and development of chrysanthemum in the vegetative phase. Acta Horticulturae (in press).

Klapwijk, D., 1987b. Effect of seasonal radiation and daylength shifts on growth and development of spray carnation. 2. Flower initiation. Netherlands Journal of Agricultural Science 35 (in press).

Klapwijk, D. and N. v. Berkel, 1982. Effect of season on growth and development of young cucumber plants. Proceedings 21th International Horticultural Congress (Hamburg), Vol. 1: 1638. 